\title{
EVALUASI KESELAMATAN DAN KESEHATAN KERJA PADA PRAKTIKUM PERANCANGAN TEKNIK INDUSTRI II MENGGUNAKAN METODE JOB SAFETY ANALYSIS
}

\author{
Rina Sulistiyowati*), Bambang Suhardi, Eko Pujiyanto \\ Program Studi Teknik Industri, Fakultas Teknik Universitas Sebelas Maret, \\ Jl. Ir. Sutami No.36A Kentingan Surakarta, Indonesia 57126
}

(Received: November 26, 2018/Accepted: February 5, 2019)

\begin{abstract}
Abstrak
Praktikum Perancangan Teknik Industri II (PPTI II) merupakan bagian dari praktikum terintegrasi di Program Studi Teknik Industri UNS yang melakukan kegiatan manufaktur dari bahan baku sampai menjadi produk. Proses manufaktur menggunakan mesin yang menimbulkan suara bising yang belum sesuai dengan Keselamatan dan Kesehatan Kerja (K3). Penelitian ini bertujuan untuk mengevaluasi K3 pada PPTI II untuk mengantisipasi terjadi kecelakaan kerja. Analisis K3 menggunakan metode Job Safety Analysis (JSA) dengan mengidentifikasi dan menganalisis potensi risiko kecelakaan kerja. Metode penelitian ini dilakukan dengan pengukuran kebisingan dan suhu serta melakukan wawancara terstruktur kepada praktikan. Pengukuran yang dilakukan adalah pengukuran kebisingan dan suhu dalam laboratorium dan untuk memperkuat hasil pengukuran dilakukan wawancara terstruktur terhadap 20 praktikan dari total praktikan yang berjumlah 71 mahasiswa kemudian melakukan analisis menggunakan JSA. Hasil penilaian tingkat risiko diketahui bahwa 66,67\% potensi risiko paling tinggi adalah karena kebisingan diatas Nilai Ambang Batas.
\end{abstract}

Kata kunci: Job Safety Analysis; Keselamatan dan Kesehatan Kerja; Praktikum Perancangan Teknik Industri II

\begin{abstract}
[Title: Work Safety and Health Evaluation on Industrial Engineering Design Practicum II using Job Safety Analysis Method] Industrial Engineering Design Practicum II (IEDP II) is part of an integrated practicum in the UNS Industrial Engineering Study Program that carry out manufacturing activities from raw materials to products. The manufacturing process uses machines that cause noise that are not in accordance with Occupational Safety and Health (OHS). This study consisted to evaluate OHS in IEDP II to anticipate workplace accidents. OHS analysis uses the Job Safety Analysis Method by identifying and analyzing the potential risk of workplace accidents. The method of this research is carried out by measuring noise and temperature and conducting structured interviews with practitioners. Measurements made were measurements of noise and temperature in the laboratory and to strengthen the results of measurements conducted structured interviews of 20 practitioners from a total of 71 students who then analyzed using JSA. The results of the risk level assessment revealed that $66.67 \%$ of the highest risk potential was due to noise.
\end{abstract}

Keywords: Job Safety Analysis; Occupational Safety and Health; Industrial Engineering Design Practicum II

\section{Pendahuluan \\ Keselamatan dan kesehatan kerja (K3) sangat diperlukan dalam suatu kegiatan manufaktur untuk}

\footnotetext{
*) Penulis Korespondensi.

E-mail: rienasulis@gmail.com
}

mengantisipasi kecelakaan kerja. Data Badan Penyelenggara Jaminan Sosial (BPJS) Ketenagakerjaan pada Januari 2016 menyatakan bahwa hingga akhir 2015 telah terjadi kecelakaan kerja sebanyak 105.182 kasus, angka tersebut menunjukkan bahwa tingkat kecelakaan kerja di Indonesia masih terbilang tinggi. (bpjsketenagakerjaan,2016). Keselamatan dan kesehatan 
kerja merupakan isu kontroversial yang paling signifikan dalam mensukseskan pengembangan industri (Jilca dan Kitaw,2017). Definisi khusus mengenai kesehatan, keselamatan dan integrasi keduanya dapat dilihat sebagai kesehatan dan keselamatan kerja adalah pendekatan holistik terhadap kesejahteraan total karyawan di tempat kerja (Amponsah dan Tawiah,2013). K3 merupakan upaya dan pemikiran untuk menjamin integritas dan kesempurnaan baik fisik maupun spiritual manusia pada umumnya dan tenaga kerja khususnya, bersama dengan hasil karyanya menuju masyarakat adil dan makmur (Tarwaka,2014). Inovasi keselamatan dan kesehatan di tempat kerja membawa pembangunan berkelanjutan melalui orang yang sehat, tempat kerja yang lebih aman, mengurangi biaya kecelakaan, lingkungan yang terkendali, kecelakaan kerja yang terkelola, dan meningkatkan pengetahuan keselamatan di tempat kerja (Jilca dan Kitaw,2017).

Praktikum merupakan kegiatan pembelajaran yang bertujuan agar siswa mendapat kesempatan untuk menguji dan mengaplikasikan teori dengan menggunakan fasilitas laboratorium baik di dalam maupun di luar laboratorium (Suryaningsih,2017). Praktikum Perancangan Teknik Industri II (PPTI II) merupakan praktikum yang melakukan kegiatan manufaktur dalam pembuatan produk kursi kuliah. PPTI II melakukan kegiatan manufaktur mulai dari kegiatan kerja bangku, milling, turning, drilling, pengelasan dan finishing. Semua proses kegiatan manufaktur untuk pembuatan kursi kuliah tersebut dilakukan di laboratorium perencanaan dan perancangan produk. PPTI II dilakukan oleh 14 kelompok. Dalam 1 shift praktikum ada 4 kelompok dengan 2 modul yang berbeda sehingga dalam laboratorium penuh dengan mahasiswa yang menyebabkan ruangan menjadi bising dan panas. Praktikan belum sepenuhnya memahami akan pentingnya $\mathrm{K} 3$ dalam kegiatan praktikum sehingga masih memerlukan analisis potensi bahaya dan risiko untuk mengetahui seberapa besar potensi bahaya dan risiko yang mungkin dapat terjadi dalam PPTI II. Kesadaran akan pentingnya $\mathrm{K} 3$ harus dimulai dari tingkat pendidikan sekolah dan perguruan tinggi melalui laboratorium yang digunakan untuk kegiatan praktikum. Risiko yang terkait dengan penelitian akademis sering dianggap jauh lebih rendah daripada risiko dalam operasi industri skala besar, pada kenyataannya laboratorium akademis dan penelitian di universitas mengandung beragam bahaya dan risiko, bahaya ini dapat menjadi signifikan jika tidak dikelola dengan baik (Olewski dan Snakard,2017). Sehingga dalam praktikum memerlukan penerapan K3 untuk mengantisipasi kecelakaan kerja.

Penerapan K3 dimulai dengan menganalisis K3 dengan penilaian bahaya dan risiko kemudian melakukan pengendalian risiko untuk mengantisipasi kecelakaan kerja. Beberapa metode yang sering dilakukan untuk menganalisa K3 antara lain ; Hazard and Operability Analysis (HAZOP), Hazard Identification and Risk Assessment (HIRA) dan Job Safety Analysis (JSA). Penelitian ini menggunakan metode JSA (Job Safety Analysis) untuk menganalisis K3 dalam PPTI II. JSA adalah metode praktis untuk mengidentifikasi, mengevaluasi dan mengendalikan risiko dalam prosedur industri (Chao dan Henshaw,2002). Penilaian risiko dengan menggunakan metode JSA yaitu mendokumentasikan semua bahaya yang mengkin terjadi pada suatu industri dan memberikan saran untuk pengendalian bahaya tersebut dengan pengembangan fasilitas stasiun kerja agar sesuai dengan aspek K3 (Gopinath dan Johansen,2016).

Beberapa penelitian sebelumnya mengatakan bahwa Metode JSA telah terbukti efektif sebagai cara paling aman dalam merencanakan suatu kegiatan (Holt,2001). JSA adalah metode pengukuran proaktif yang efisien untuk penilaian risiko keamanan yang digunakan dalam manufaktur industri (Rozenfeld dkk, 2010). Menyusun prosedur kerja dengan benar merupakan salah satu keuntungan dari menerapkan metode JSA (Sholicha dan Suliantoro,2016)

\section{Bahan dan Metode}

Penelitian ini dimulai dengan pengamatan langsung pada saat kegiatan PPTI II untuk mengetahui K3 yang belum diterapkan, selanjutnya dilakukan pengukuran kebisingan dan suhu menggunakan environmeter pada beberapa waktu yang berbeda untuk mengetahui apakah tingkat kebisingan dan suhu yang ada dalam kegiatan PPTI II masih dalam Nilai Ambang Batas (NAB). Cara pengukuran kebisingan dan suhu pada saat praktikum berlangsung dilakukan dengan jarak pengukuran 1 meter di atas lantai dan $80 \mathrm{~cm}$ di samping mesin yang sedang beroperasi. Sekali pengukuran dilakukan 6 kali pengukuran dan diambil rata - rata nilai yang diperoleh. Untuk memperkuat hasil pengamatan dan pengukuran selanjutnya adalah melakukan wawancara yang menggunakan metode wawancara terstruktur. Wawancara dilakukan terhadap 20 orang mahasiswa peserta praktikum.

Metode yang akan digunakan dalam penelitian ini adalah metode JSA (Job Safety Analysis). JSA adalah metode praktis untuk mengidentifikasi, mengevaluasi dan mengendalikan risiko dalam prosedur industri (Chao dan Henshaw, 2002).

Proses JSA mencakup tiga tahap utama (Chao dan Henshaw, 2002), yaitu:

1. Identifikasi, memilih pekerjaan atau aktivitas tertentu dan memecahnya menjadi serangkaian tahapan, kemudian mengidentifikasi semua kemungkinan insiden kehilangan kontrol yang mungkin terjadi selama bekerja.

2. Penilaian, mengevaluasi tingkat relatif risiko untuk semua insiden yang teridentifikasi. 
3. Tindakan, mengendalikan risiko dengan mengambil langkah-langkah yang cukup untuk mengurangi atau menghilangkannya.

JSA melakukan penilaian risiko untuk menentukan besarnya tingkat risiko atau Risk Rating Number (RRN) menggunakan rumus :

\section{$\mathrm{RRN}=$ Likelihood $\mathrm{x}$ Severity}

Dimana:

Likelihood $=$ Frekuensi kejadian

Severity = Tingkat keparahan yang ditimbulkan

PPTI II terbagi dalam 6 stasiun kerja yaitu :
1. Stasiun kerja bangku yang melakukan pengukuran, pemotongan dan penekukan secara manual dengan perkakas tangan. Hasil dari JSA stasiun kerja bangku dapat dilihat dalam Tabel 1.

Tabel 1 menjelaskan JSA pada stasiun kerja bangku yang menerangkan uraian kegiatan dalam stasiun kerja bangku,melakukan penilaian likelyhood dan severity, kemudian menghitung RRN dengan mengalikan likelyhood dengan severity selanjutnya melakukan rekomendasi pengendalian setiap uraian kegiatan. Tabel JSA selanjutnya yaitu stasiun kerja milling yang akan diterangkan dalam Tabel 2.

Tabel 1. JSA Stasiun Kerja Bangku

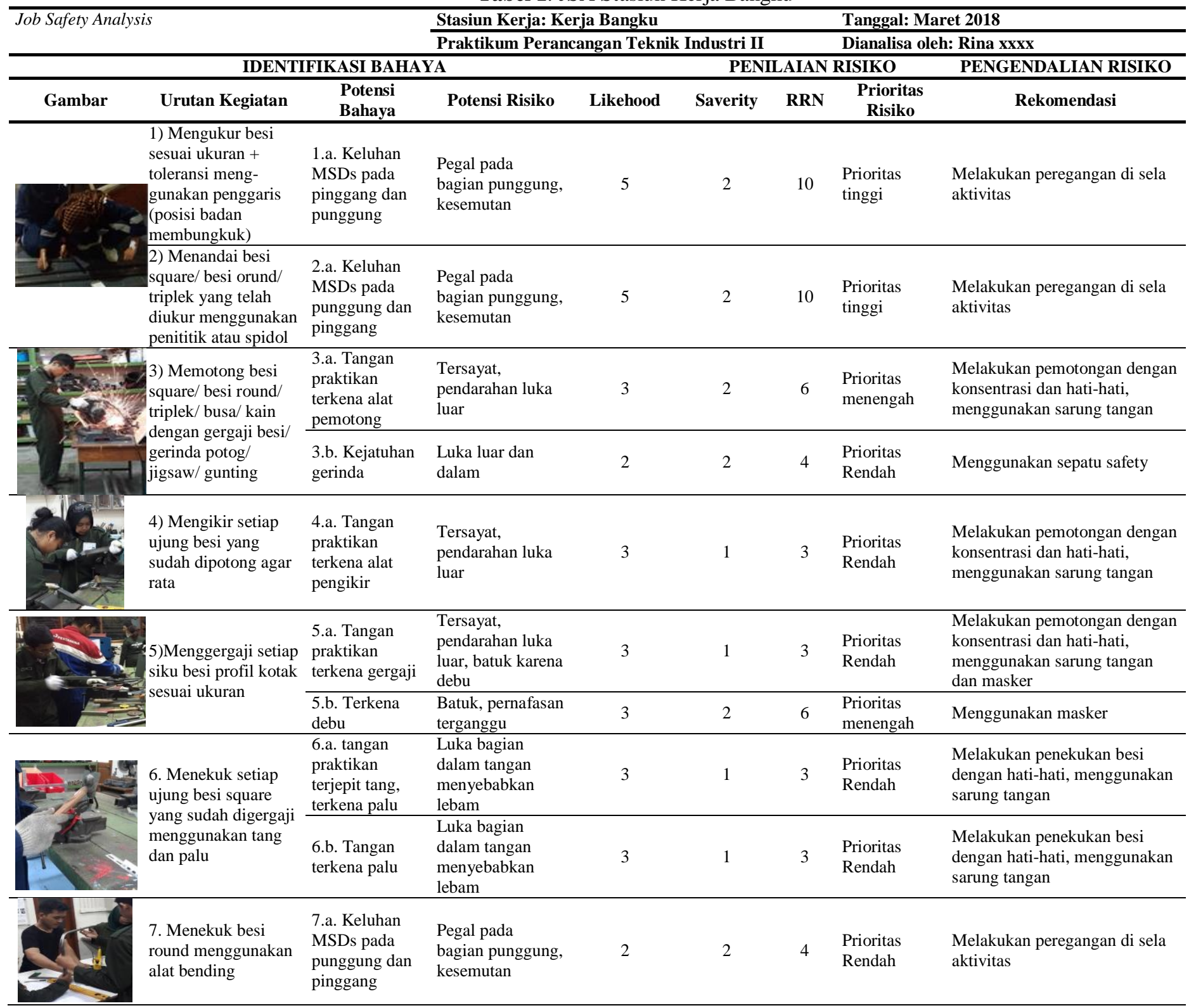


Tabel 2. JSA Stasiun Kerja Milling

\begin{tabular}{|c|c|c|c|c|c|c|c|c|}
\hline \multirow{2}{*}{\multicolumn{3}{|c|}{ Job Safety Analysis }} & \multicolumn{4}{|c|}{ Stasiun Kerja: Milling } & \multicolumn{2}{|c|}{ Tanggal: Maret 2018} \\
\hline & & & \multicolumn{4}{|c|}{ Praktikum Perancangan Teknik Industri II } & \multicolumn{2}{|c|}{ Dianalisa oleh: Rina $x \times x x$} \\
\hline \multicolumn{5}{|c|}{ IDENTIFIKASI BAHAYA } & \multicolumn{3}{|c|}{ PENILAIAN RISIKO } & \multirow{2}{*}{$\begin{array}{c}\text { PENGENDALIAN RISIKO } \\
\text { Rekomendasi }\end{array}$} \\
\hline Gambar & Urutan Kegiatan & $\begin{array}{l}\text { Potensi } \\
\text { Bahaya }\end{array}$ & Potensi Risiko & Likehood & Saverity & RRN & $\begin{array}{c}\text { Prioritas } \\
\text { Risiko }\end{array}$ & \\
\hline & $\begin{array}{l}\text { 1) Set up mesin } \\
\text { milling; kecepatan, } \\
\text { diameter pahat } \\
\text { milling, memasang } \\
\text { pahat end mill }\end{array}$ & $\begin{array}{l}\text { 1.a. Tangan } \\
\text { praktikan pahat }\end{array}$ & Tersayat & 2 & 1 & 2 & $\begin{array}{l}\text { Prioritas } \\
\text { rendah }\end{array}$ & $\begin{array}{l}\text { Melakukan set up sesuai SOP } \\
\text { dan harus hati-hati, } \\
\text { menggunakan kacamata, sarung } \\
\text { tangan, dan masker }\end{array}$ \\
\hline \multirow{4}{*}{ 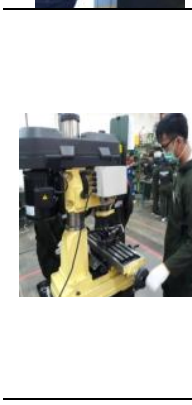 } & \multirow{4}{*}{$\begin{array}{l}\text { 2) Melakukan facing } \\
\text { pada seluruh } \\
\text { permukaan bahan }\end{array}$} & $\begin{array}{l}\text { 2.a. Tangan } \\
\text { terkena mesin } \\
\text { milling }\end{array}$ & Luka pendarahan & 2 & 2 & 4 & $\begin{array}{l}\text { Prioritas } \\
\text { rendah }\end{array}$ & $\begin{array}{l}\text { Menggunakan sarung tangan, } \\
\text { ear plug, kaca mata, dan masker }\end{array}$ \\
\hline & & $\begin{array}{l}\text { 2.b. Tangan } \\
\text { terkea debu } \\
\text { geram }\end{array}$ & $\begin{array}{l}\text { Batuk/ pernafasan } \\
\text { terganggu }\end{array}$ & 4 & 2 & 8 & $\begin{array}{l}\text { Prioritas } \\
\text { menengah }\end{array}$ & $\begin{array}{l}\text { Menggunakan masker dan kaca } \\
\text { mata }\end{array}$ \\
\hline & & $\begin{array}{l}\text { 2.c. Salah set } \\
\text { up }\end{array}$ & $\begin{array}{l}\text { Terkena pahat } \\
\text { atau benda kerja } \\
\text { yang terlempar }\end{array}$ & 3 & 2 & 6 & $\begin{array}{l}\text { Prioritas } \\
\text { menengah }\end{array}$ & $\begin{array}{l}\text { Menggunakan kacamata, } \\
\text { wearpack, dan berhati-hati, } \\
\text { konsentrasi dalam set up }\end{array}$ \\
\hline & & $\begin{array}{l}\text { 2.d. Kebisingan } \\
\text { di atas NAB }\end{array}$ & $\begin{array}{l}\text { Pendengaran } \\
\text { terganggu/ } \\
\text { bermasalah }\end{array}$ & 5 & 2 & 10 & $\begin{array}{l}\text { Prioritas } \\
\text { tinggi }\end{array}$ & $\begin{array}{l}\text { Menggunakan ear plug, } \\
\text { mengurangi proses waktu kerja }\end{array}$ \\
\hline & \multirow{3}{*}{$\begin{array}{l}\text { 3) Melakukan } \\
\text { roughing sesuai } \\
\text { ukuran } \\
\text { menggunakan } \\
\text { pahat yang sesuai }\end{array}$} & $\begin{array}{l}\text { 3.a. Tangan } \\
\text { Praktikan } \\
\text { terkena mesin } \\
\text { milling } \\
\end{array}$ & Luka pendarahan & 2 & 2 & 4 & $\begin{array}{l}\text { Prioritas } \\
\text { rendah }\end{array}$ & $\begin{array}{l}\text { Menggunakan sarung tangan, } \\
\text { ear plug, kacamata, dan masker }\end{array}$ \\
\hline & & $\begin{array}{l}\text { 3.b. Terkena } \\
\text { debu geram }\end{array}$ & $\begin{array}{l}\text { Batuk/ pernafasan } \\
\text { terganggu }\end{array}$ & 4 & 2 & 8 & $\begin{array}{l}\text { Prioritas } \\
\text { menengah }\end{array}$ & $\begin{array}{l}\text { Menggunakan masker dan } \\
\text { kacamata }\end{array}$ \\
\hline & & $\begin{array}{l}\text { 3.c. Kebisingan } \\
\text { di atas NAB }\end{array}$ & $\begin{array}{l}\text { Pendengan } \\
\text { terganggu }\end{array}$ & 5 & 2 & 10 & $\begin{array}{l}\text { Prioritas } \\
\text { tinggi }\end{array}$ & $\begin{array}{l}\text { Menggunakan ear plug, } \\
\text { mengurangi proses waktu kerja }\end{array}$ \\
\hline & $\begin{array}{l}\text { 4) Set up mesin } \\
\text { milling untuk } \\
\text { melepas benda } \\
\text { kerja }\end{array}$ & $\begin{array}{l}\text { 4.a. Tangan } \\
\text { praktikan pahat }\end{array}$ & Tersayat & 2 & 1 & 2 & $\begin{array}{l}\text { Prioritas } \\
\text { rendah }\end{array}$ & $\begin{array}{l}\text { Melakukan set up sesuai SOP } \\
\text { dan harus hati-hati, } \\
\text { menggunakan kacamata, sarung } \\
\text { tangan dan masker }\end{array}$ \\
\hline
\end{tabular}

2. Stasiun kerja milling merupakan stasiun kerja yang menggunakan mesin milling untuk membentuk suatu permukaan dengan ukuran dan kualitas tertentu sesuai dengan bentuk yang diinginkan dalam produk. JSA dari stasiun kerja milling diterangkan dalam Tabel 2.

Setelah melakukan penilaian JSA pada stasiun kerja milling kemudian melakukan penilaian JSA dengan membuat tabel JSA pada stasiun kerja turning yang dapat dilihat pada Tabel 3.

3. Stasiun kerja turning yang menggunakan mesin turning untuk melakukan proses pembubutan sesuai dengan ukuran dan bentuk yang diperlukan. JSA dari stasiun kerja turning diterangkan dalam Tabel 3.

Tabel 3 menerangkan bahwa pada stasiun kerja turning melakukan kegiatan lebih banyak daripada stasiun kerja bangku dan stasiun kerja milling. Proses selanjutnya adalah dengan membuat tabel JSA stasiun berikutnya yaitu stasiun kerja drilling yang dapat dilihat pada Tabel 4.

4. Stasiun kerja drilling merupakan stasiun kerja yang melakukan proses pelubangan sesuai ukuran tertentu yang telah ditentukan dalam pembuatan produk kursi kuliah menggunakan mesin drilling. JSA dari stasiun kerja drilling diterangkan dalam Tabel 4.

Tabel 4 yang menerangkan uraian kegiatan dan penilaian pada stasiun kerja drilling, selanjutnya melakukan penilaian stasiun kerja pengelasan dengan membuat tabel JSA stasiun kerja pengelasan yang akan diterangkan pada Tabel 5.

5. Stasiun kerja pengelasan merupakan stasiun yang melakukan penyambungan benda kerja menggunakan mesin las dan elektroda. JSA dari stasiun kerja pengelasan diterangkan dalam Tabel 5. Setelah melakukan penilaian JSA pada stasiun kerja pengelasan, selanjutnya melakukan penilaian JSA dengan membuat tabel JSA stasiun kerja finishing yang dapat dilihat pada Tabel 6.

6. Stasiun kerja finishing melakukan pemolesan, penghalusan, pengecatan agar produk mempunyai nilai tambah. JSA dari stasiun kerja finishing diterangkan dalam Tabel 6.

JSA stasiun kerja finishing pada Tabel 6. merupakan stasiun kerja terakhir dalam proses manufaktur pada PPTI II. 
Tabel 3. JSA Stasiun Kerja Turning

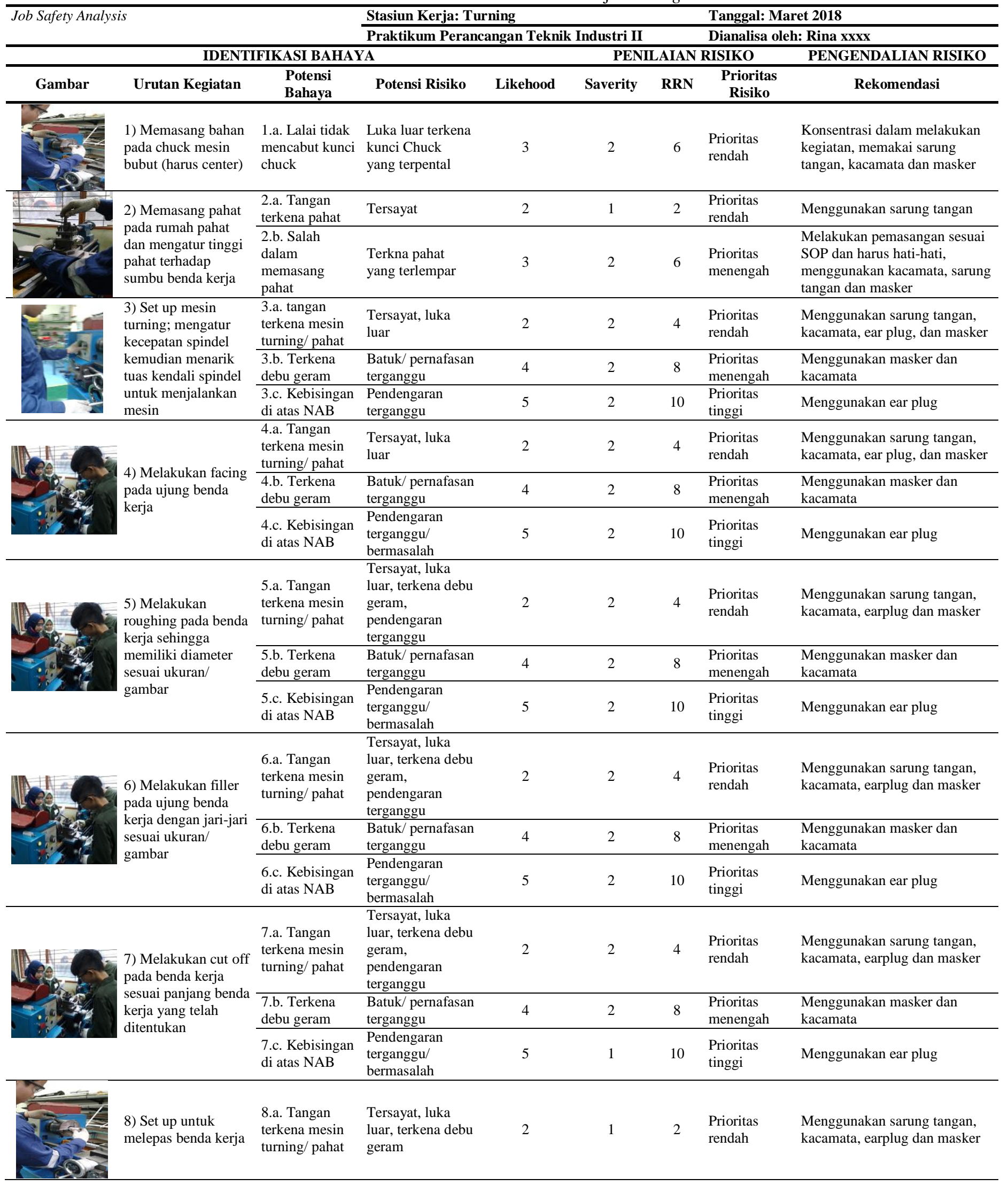


Tabel 4. JSA Stasiun Kerja Drilling

\begin{tabular}{|c|c|c|c|c|c|c|c|c|}
\hline \multirow{2}{*}{\multicolumn{3}{|c|}{ Job Safety Analysis }} & \multicolumn{4}{|c|}{ Stasiun Kerja: Drilling } & \multicolumn{2}{|c|}{ Tanggal: Maret 2018} \\
\hline & & & \multicolumn{4}{|c|}{ Praktikum Perancangan Teknik Industri II } & \multicolumn{2}{|c|}{ Dianalisa oleh: Rina xxxx } \\
\hline \multicolumn{5}{|c|}{ IDENTIFIKASI BAHAYA } & \multicolumn{3}{|c|}{ PENILAIAN RISIKO } & \multirow{2}{*}{$\begin{array}{c}\text { PENGENDALIAN RISIKO } \\
\text { Rekomendasi }\end{array}$} \\
\hline Gambar & Urutan Kegiatan & $\begin{array}{l}\text { Potensi } \\
\text { Bahaya } \\
\end{array}$ & Potensi Risiko & Likehood & Saverity & RRN & $\begin{array}{c}\text { Prioritas } \\
\text { Risiko } \\
\end{array}$ & \\
\hline & $\begin{array}{l}\text { 1) Set up mesin } \\
\text { Drilling; mencekam } \\
\text { mata bor }\end{array}$ & $\begin{array}{l}\text { 1.a. Tangan } \\
\text { terkena ujung } \\
\text { mata bor }\end{array}$ & $\begin{array}{l}\text { Tersayat, luka } \\
\text { luar, terkena debu } \\
\text { geram }\end{array}$ & 2 & 1 & 2 & $\begin{array}{l}\text { Prioritas } \\
\text { rendah }\end{array}$ & $\begin{array}{l}\text { Menggunakan sarung tangan, } \\
\text { kacamata, ear plug, dan masker }\end{array}$ \\
\hline & $\begin{array}{l}\text { 2) Mencekam benda } \\
\text { kerja menggunakan } \\
\text { ragum }\end{array}$ & $\begin{array}{l}\text { 2.a. Tangan } \\
\text { terjepit ragum }\end{array}$ & $\begin{array}{l}\text { Luka bagian } \\
\text { dalam kulit, luka } \\
\text { luar }\end{array}$ & 2 & 2 & 4 & $\begin{array}{l}\text { Prioritas } \\
\text { rendah }\end{array}$ & $\begin{array}{l}\text { Melakukan pemasangan sesuai } \\
\text { SOP dan harus hati-hati, } \\
\text { menggunakan kacamata, sarung } \\
\text { tangan, dan masker }\end{array}$ \\
\hline & & $\begin{array}{l}\text { 3.a. Tangan } \\
\text { terkena pahat }\end{array}$ & $\begin{array}{l}\text { Tersayat, luka } \\
\text { luar }\end{array}$ & 3 & 2 & 6 & $\begin{array}{l}\text { Prioritas } \\
\text { menengah }\end{array}$ & $\begin{array}{l}\text { Menggunakan sarung tangan, } \\
\text { kacamata, ear plug, dan masker }\end{array}$ \\
\hline & pengeboran pada & $\begin{array}{l}\text { 3.b. Terkena } \\
\text { debu geram }\end{array}$ & $\begin{array}{l}\text { Batuk/ pernafasan } \\
\text { terganggu }\end{array}$ & 4 & 2 & 8 & $\begin{array}{l}\text { Prioritas } \\
\text { menengah }\end{array}$ & $\begin{array}{l}\text { Menggunakan masker dan } \\
\text { kacamata }\end{array}$ \\
\hline & $\begin{array}{l}\text { benda Kerja (besi } \\
\text { square \& round) }\end{array}$ & $\begin{array}{l}\text { 3.c. Kebisingan } \\
\text { di atas NAB }\end{array}$ & $\begin{array}{l}\text { Pendengaran } \\
\text { terganggu/ } \\
\text { bermasalah }\end{array}$ & 5 & 2 & 10 & $\begin{array}{l}\text { Prioritas } \\
\text { tinggi }\end{array}$ & Menggunakan ear plug \\
\hline & $\begin{array}{l}\text { 4) Melakukan facing } \\
\text { pada ujung benda } \\
\text { kerja }\end{array}$ & $\begin{array}{l}\text { 4.a. Tangan } \\
\text { terkena ujung } \\
\text { mata bor }\end{array}$ & $\begin{array}{l}\text { Tersayat, luka } \\
\text { luar, terkena debu } \\
\text { geram }\end{array}$ & 2 & 1 & 2 & $\begin{array}{l}\text { Prioritas } \\
\text { rendah }\end{array}$ & $\begin{array}{l}\text { Menggunakan sarung tangan, } \\
\text { kacamata, ear plug, dan masker }\end{array}$ \\
\hline
\end{tabular}

Tabel 5. JSA Stasiun Kerja Pengelasan

\begin{tabular}{|c|c|c|c|c|c|c|c|c|}
\hline \multirow{2}{*}{\multicolumn{3}{|c|}{ Job Safety Analysis }} & \multicolumn{4}{|c|}{ Stasiun Kerja: Pengelasan } & \multicolumn{2}{|c|}{ Tanggal: Maret 2018} \\
\hline & & & \multicolumn{4}{|c|}{ Praktikum Perancangan Teknik Industri II } & \multicolumn{2}{|c|}{ Dianalisa oleh: Rina xxxx } \\
\hline \multicolumn{5}{|c|}{ IDENTIFIKASI BAHAYA } & \multicolumn{3}{|c|}{ PENILAIAN RISIKO } & \multirow{2}{*}{$\begin{array}{c}\text { PENGENDALIAN RISIKO } \\
\text { Rekomendasi }\end{array}$} \\
\hline Gambar & Urutan Kegiatan & $\begin{array}{l}\text { Potensi } \\
\text { Bahaya }\end{array}$ & Potensi Risiko & Likehood & Saverity & RRN & $\begin{array}{c}\text { Prioritas } \\
\text { Risiko }\end{array}$ & \\
\hline & $\begin{array}{l}\text { 1) Menyiapkan } \\
\text { benda kerja yang } \\
\text { akan dilas; benda } \\
\text { kerja (besi square \& } \\
\text { round, besi plat) dan } \\
\text { posisi benda kerja }\end{array}$ & $\begin{array}{l}\text { 1.a. Benda } \\
\text { kerja terjatuh }\end{array}$ & $\begin{array}{l}\text { Kejatuha benda } \\
\text { kerja, luka ringan }\end{array}$ & 2 & 1 & 2 & $\begin{array}{l}\text { Prioritas } \\
\text { rendah }\end{array}$ & $\begin{array}{l}\text { Menggunakan sepatu safety, } \\
\text { hati-hati dalam melakukan } \\
\text { pengambilan benda kerja }\end{array}$ \\
\hline & $\begin{array}{l}\text { 2) Set up mesin las; } \\
\text { mengatur arus las } \\
\text { (ampere) dan } \\
\text { polaritas } \\
\text { (penyesuaian dengan } \\
\text { material benda kerja) }\end{array}$ & $\begin{array}{l}\text { 2.a. Tersengat } \\
\text { arus listrik }\end{array}$ & Luka ringan & 2 & 2 & 4 & $\begin{array}{l}\text { Prioritas } \\
\text { rendah }\end{array}$ & $\begin{array}{l}\text { Dilakukan maintenance berkala } \\
\text { terhadap alat las, menggunakan } \\
\text { sarung tangan, menggunakan } \\
\text { sepatu }\end{array}$ \\
\hline & $\begin{array}{l}\text { 3) Melakukan } \\
\text { pengelasan pada } \\
\text { benda kerja }\end{array}$ & $\begin{array}{l}\text { 3.a. Tangan } \\
\text { dan wajah } \\
\text { terkena } \\
\text { percikan api las }\end{array}$ & $\begin{array}{l}\text { Tangan atau } \\
\text { bagian wajah } \\
\text { melepuh }\end{array}$ & 5 & 2 & 10 & $\begin{array}{l}\text { Prioritas } \\
\text { tinggi }\end{array}$ & $\begin{array}{l}\text { Menggunakan penutup wajah } \\
\text { atau topeng las, menggunakan } \\
\text { sarung tangan dan ear plug }\end{array}$ \\
\hline & $\begin{array}{l}\text { 4) Membersihkan } \\
\text { hasil pengelasan }\end{array}$ & $\begin{array}{l}\text { 4.a. Tangan } \\
\text { terkena panas } \\
\text { terak las }\end{array}$ & Tangan melepuh & 3 & 2 & 6 & $\begin{array}{l}\text { Prioritas } \\
\text { menengah }\end{array}$ & $\begin{array}{l}\text { Menggunakan sarung tangan } \\
\text { dan ear plug }\end{array}$ \\
\hline 1 & $\begin{array}{l}\text { 5) Set up untuk } \\
\text { melepas benda kerja }\end{array}$ & $\begin{array}{l}\text { 5.a. benda kerja } \\
\text { terjatuh }\end{array}$ & $\begin{array}{l}\text { Kaki kejatuhan } \\
\text { benda kerja, luka } \\
\text { ringan }\end{array}$ & 2 & 1 & 2 & $\begin{array}{l}\text { Prioritas } \\
\text { rendah }\end{array}$ & $\begin{array}{l}\text { Menggunakan sepatu safety, } \\
\text { hati-hati dalam melepas benda } \\
\text { kerja }\end{array}$ \\
\hline
\end{tabular}


Tabel 6. JSA Stasiun Kerja Finishing

\begin{tabular}{|c|c|c|c|c|c|c|c|c|}
\hline \multirow{2}{*}{\multicolumn{3}{|c|}{ Job Safety Analysis }} & \multicolumn{4}{|c|}{ Stasiun Kerja: Finishing } & \multicolumn{2}{|c|}{ Tanggal: Maret 2018} \\
\hline & & & \multicolumn{4}{|c|}{ Praktikum Perancangan Teknik Industri II } & \multicolumn{2}{|c|}{ Dianalisa oleh: Rina xxxx } \\
\hline \multicolumn{5}{|c|}{ IDENTIFIKASI BAHAYA } & \multicolumn{3}{|c|}{ PENILAIAN RISIKO } & \multirow{2}{*}{$\begin{array}{c}\text { PENGENDALIAN RISIKO } \\
\text { Rekomendasi } \\
\end{array}$} \\
\hline Gambar & Urutan Kegiatan & $\begin{array}{l}\text { Potensi } \\
\text { Bahaya } \\
\end{array}$ & Potensi Risiko & Likehood & Saverity & RRN & $\begin{array}{c}\text { Prioritas } \\
\text { Risiko } \\
\end{array}$ & \\
\hline & $\begin{array}{l}\text { 1) Menyiapkan } \\
\text { benda kerja }\end{array}$ & $\begin{array}{l}\text { 1.a. Benda } \\
\text { kerja terjatuh }\end{array}$ & $\begin{array}{l}\text { Kejatuhan benda } \\
\text { kerja dalam } \\
\text { proses } \\
\text { pengambilan }\end{array}$ & 2 & 1 & 2 & $\begin{array}{l}\text { Prioritas } \\
\text { rendah }\end{array}$ & $\begin{array}{l}\text { Menggunakan sepatu safety, } \\
\text { menggunakan troli pada saat } \\
\text { pengambilan }\end{array}$ \\
\hline & $\begin{array}{l}\text { 2) Melakukan } \\
\text { pengamplasan pada } \\
\text { benda kerja (rangka } \\
\text { kursi) }\end{array}$ & $\begin{array}{l}\text { 2.a. Keluhan } \\
\text { MSDs pada } \\
\text { punggug dan } \\
\text { pinggang }\end{array}$ & $\begin{array}{l}\text { Pegal pada } \\
\text { bagian punggung, } \\
\text { kesemutan }\end{array}$ & 3 & 2 & 6 & $\begin{array}{l}\text { Prioritas } \\
\text { rendah }\end{array}$ & $\begin{array}{l}\text { Melakukan peregangan di sela } \\
\text { aktivitas }\end{array}$ \\
\hline & & $\begin{array}{l}\text { 2.b. Tangan } \\
\text { terkena bagian } \\
\text { kursi yang } \\
\text { tajam }\end{array}$ & $\begin{array}{l}\text { Tergores, luka } \\
\text { pendarahan luar }\end{array}$ & 3 & 1 & 3 & $\begin{array}{l}\text { Prioritas } \\
\text { tinggi }\end{array}$ & Menggunakan sarung tangan \\
\hline & $\begin{array}{l}\text { 3) Melakukan set up } \\
\text { alat pengecatan; } \\
\text { kompresor, spray } \\
\text { gun }\end{array}$ & $\begin{array}{l}\text { 4.a. Tersengat } \\
\text { arus listrik }\end{array}$ & Luka ringan & 2 & 2 & 4 & $\begin{array}{l}\text { Prioritas } \\
\text { rendah }\end{array}$ & $\begin{array}{l}\text { Menggunakan wearpack, } \\
\text { menggunakan sarung tangan } \\
\text { anti cairan (sarung tangan } \\
\text { karet) }\end{array}$ \\
\hline & $\begin{array}{l}\text { 4) Mencampur cat } \\
\text { dengan tinner } \\
\text { kemudian } \\
\text { dimasukkan ke } \\
\text { dalam spray gun }\end{array}$ & $\begin{array}{l}\text { 4.a. Terkea } \\
\text { tumpahan cat } \\
\text { atau tinner }\end{array}$ & $\begin{array}{l}\text { Baju kotor, } \\
\text { tangan panas }\end{array}$ & 4 & 1 & 4 & $\begin{array}{l}\text { Prioritas } \\
\text { rendah }\end{array}$ & $\begin{array}{l}\text { Menggunakan wearpack, } \\
\text { menggunakan sarung tangan } \\
\text { anti cairan (sarung tangan } \\
\text { karet) }\end{array}$ \\
\hline & $\begin{array}{l}\text { 5) Melakukan } \\
\text { pengecatan pada } \\
\text { seluruh bagian } \\
\text { rangka kursi }\end{array}$ & $\begin{array}{l}\text { 5.a. Bagian } \\
\text { wajah terkena } \\
\text { semprotan cat }\end{array}$ & $\begin{array}{l}\text { Sesak nafas, mata } \\
\text { perih }\end{array}$ & 5 & 2 & 10 & $\begin{array}{l}\text { Prioritas } \\
\text { tinggi }\end{array}$ & $\begin{array}{l}\text { Menurunkan posisi ketinggian } \\
\text { benda kerja menggunakan } \\
\text { masker, kacamata, dan sarung } \\
\text { tangan }\end{array}$ \\
\hline
\end{tabular}

\section{Hasil dan Pembahasan}

Hasil pengukuran kebisingan dan suhu pada praktikum menunjukkan bahwa kebisingan berada antara 90 dBA sampai 92 dB dengan nilai pengukuran kebisingan yang paling tinggi diperoleh dari pengukuran pada mesin Turning dan Milling, kemudian dilanjutkan mesin Drilling. Sesuai dengan Permenaker No.5 (2018) Nilai Ambang Batas (NAB) yang diijinkan dalam batas kebisingan $92 \mathrm{dBA}$ adalah 2 jam, sesuai jadwal pada kegiatan PPTI II bahwa praktikum dilaksanakan selama 3,5 jam sehingga nilai kebisingan yang terjadi dalam PPTI II sudah berada di atas NAB. Suhu yang diperoleh dari hasil pengukuran menunjukkan bahwa pada PPTI II suhu udara berada diantara $29^{\circ} \mathrm{C}$ sampai dengan $32^{\circ} \mathrm{C}$. Menurut Permenaker No.5 (2018) menyatakan bahwa untuk pekerjaan pada suhu $28^{\circ} \mathrm{C}$ sampai $31^{\circ} \mathrm{C}$ dengan durasi waktu di atas 75 menit maka harus dilakukan 2 kali istirahat normal sehingga dapat diketahui bahwa suhu udara pada PPTI II juga berada di atas NAB. Untuk memperkuat hasil pengukuran selanjutnya melakukan wawancara terhadap 20 mahasiswa peserta praktikum. Hasil dari jawaban praktikan yang menyatakan ' $Y a$ ' dalam setiap pertanyaan dapat dilihat dalam diagram Pareto pada Gambar 1. Dalam gambar tersebut menunjukkan semua peserta wawancara menyatakan bahwa terdapat debu (faktor kimia), bising dan panas (faktor fisik) dan keluhan MSDs karena terlalu sering membungkuk dalam stasiun kerja bangku (faktor ergonomis). 


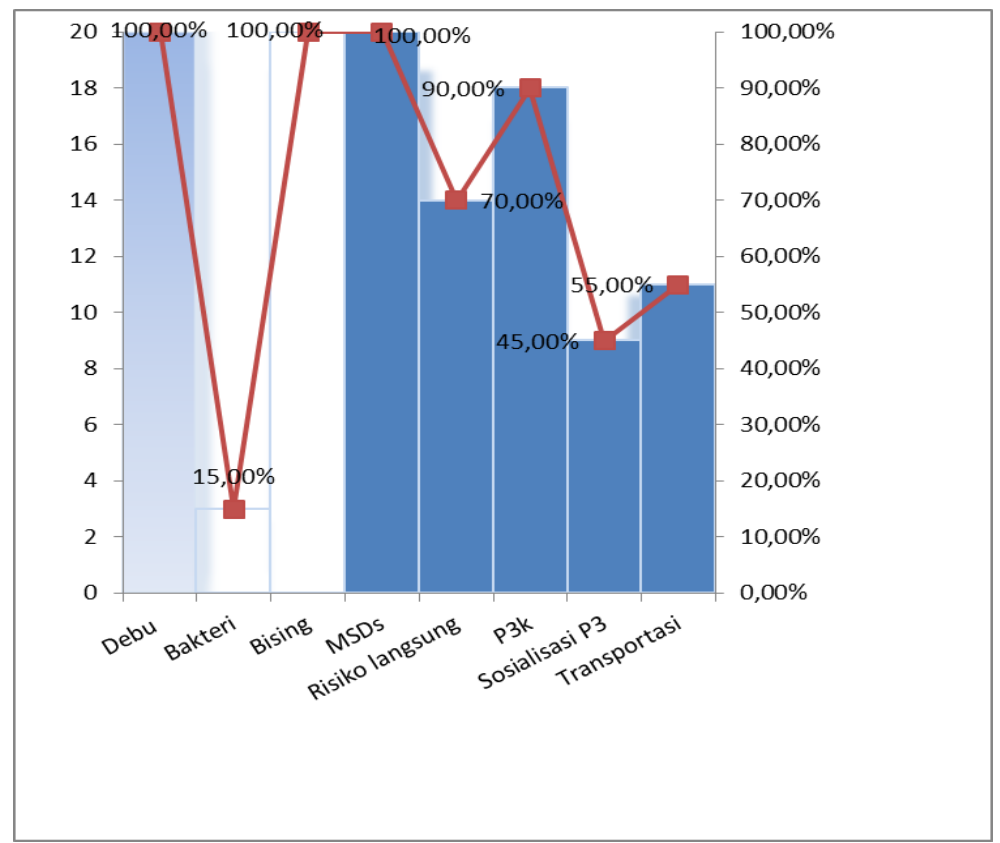

Gambar 1. Pareto Hasil Wawancara Jawaban 'Ya'

Tabel 7. Penilaian Tingkat Risiko pada PPTI II

\begin{tabular}{lccc}
\hline \multicolumn{1}{c}{ Stasiun } & $\begin{array}{c}\text { Prioritas } \\
\text { Rendah }\end{array}$ & $\begin{array}{c}\text { Prioritas } \\
\text { Menengah }\end{array}$ & $\begin{array}{c}\text { Prioritas } \\
\text { Utama }\end{array}$ \\
\hline $\begin{array}{l}\text { Kerja } \\
\text { Bangku }\end{array}$ & 5 & 3 & 2 \\
\hline Milling & 4 & 3 & 2 \\
\hline Turning & 7 & 7 & 5 \\
\hline Drilling & 3 & 2 & 1 \\
\hline Pengelasan & 3 & 1 & 1 \\
\hline Finishing & 4 & 1 & 1 \\
\hline $\begin{array}{l}\text { Total Uraian } \\
\text { Kegiatan }\end{array}$ & 26 & 17 & 12 \\
\hline
\end{tabular}

Gambar 1 menunjukkan bahwa keluhan terhadap debu geram, kebisingan dan MSDs mempunyai prosentase $100 \%$ sehingga dapat diketahui bahwa seluruh peserta praktikum mempunyai keluhan yang sama mengenai gangguan debu, kebisingan dan MSDs. Maka untuk mengetahui apakah ketiga hal tersebut merupakan tingkat risiko yang tinggi maka perlu melakukan penilaian RRN.

Dari data JSA pada Tabel 1 sampai dengan Tabel 6 dihitung nilai RRN masing masing uraian kegiatan dalam stasiun kerja. Nilai yang diperoleh kemudian dibuat dalam tabel yang akan menunjukkan bahwa potensi bahaya masuk dalam kriteria potensi bahaya dengan tingkat risiko rendah, menengah atau utama. Hasil kategori tingkat prioritas maka potensi bahaya tersebut dapat dilakukan pencegahan dan perbaikan (Solicha dan Sulistoro, 2016).

Penilaian tingkat risiko yang diperoleh dari perhitungan RRN menunjukkan hasil pada Tabel 7.
Tabel 7 menunjukkan ada 12 uraian kegiatan dalam PPTI II yang termasuk dalam potensi risiko prioritas utama yang artinya potensi risiko tersebut memerlukan perbaikan segera untuk mencegah atau mengurangi kecelakaan kerja maupun penyakit akibat kerja dalam jangka pendek atau jangka panjang.

\section{Pembahasan}

Penelitian ini bertujuan untuk mengevaluasi K3 pada PPTI II dengan menganalisis potensi bahaya dan potensi risiko yang terjadi untuk mencegah kemungkinan terjadi kecelakaan kerja atau penyakit akibat kerja baik jangka pendek maupun jangka panjang. Potensi risiko yang akan dibahas hanya pada potensi risiko prioritas utama karena pada tinkat risiko prioritas utama harus segera dilakukan perbaikan untuk mencegah kecelakaan kerja. Potensi bahaya yang akan menimbulkan potensi risiko pada prioritas utama diterangkan dalam Tabel 8. 
Pada Tabel 8 menjelaskan bahwa potensi bahaya yang paling tinggi pada tingkat risiko prioritas utama adalah kebisingan diatas NAB. Untuk menjelaskan lebih detail maka dibuat persentase jumlah masing - masing potensi bahaya pada tingkat risiko prioritas utama yang dapat dilihat dalam diagram Pareto pada Gambar 2.

Tabel 8. Potensi Bahaya dengan Tingkat Risiko Prioritas Utama

\begin{tabular}{lc}
\hline \multicolumn{1}{c}{ Potensi Bahaya } & Jumlah \\
\hline Keluhan MSDs pada punggung dan pinggang & 2 \\
\hline Kebisingan di atas NAB & 8 \\
\hline Tangann/ wajah terkena percikan api & 1 \\
\hline Wajah terkena semprot cat & 1 \\
\hline Jumlah & 12 \\
\hline
\end{tabular}

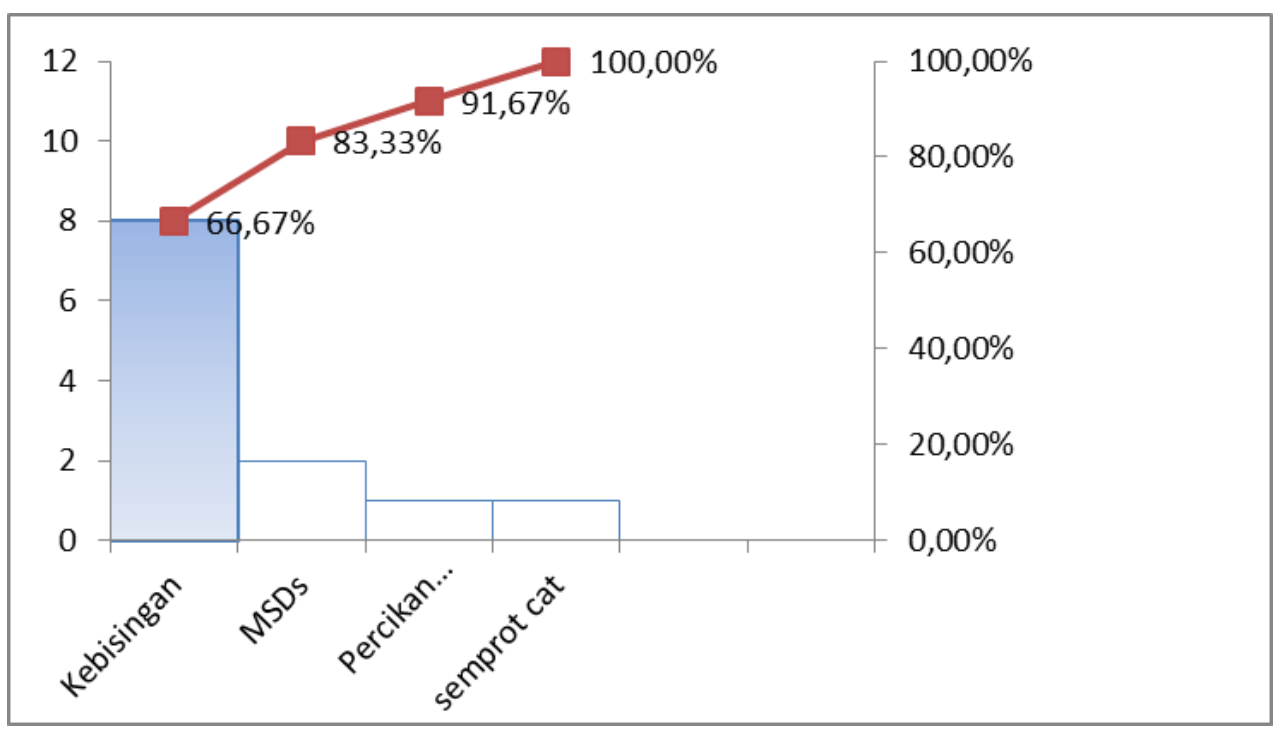

Gambar 2. Diagram Pareto Potensi Risiko Prioritas Utama

Diagram Pareto pada Gambar 2 menunjukkan potensi risiko karena kebisingan sebesar $66 \%$ dari seluruh jumlah potensi bahaya pada yang terdapat dalam potensi risiko prioritas utama. Sehingga dapat diketahui bahwa dalam PPTI II masih memerlukan manajemen K3 untuk melakukan tindakan pengendalian potensi risiko utama baik dengan tindakan rekayasa teknik atau rekayasa manajemen untuk mencegah dampak kebisingan pada peserta praktikum. Dampak yang terjadi akibat kebisingan berupa gangguan komunikasi, gangguan pendengaran dan gangguan psikologis (Fithri \& Annisa, 2015). Rekayasa teknik dapat dilakukan dengan mengatur ulang tata letak mesin - mesin yang ada di laboratorium namun dalam waktu dekat rekayasa teknik belum memungkinkan untuk dilakukan karena terkendala biaya dalam perubahan tata letak. Rekayasa manajemen dapat dilakukan dengan mengubah jadwal praktikum agar praktikan tidak terpapar kebisingan di atas NAB. Pembuatan SOP juga dapat digunakan sebagai salah satu tindakan perbaikan dari rekayasa manajemen. Rekayasa manajemen merupakan tindakan pencegahan yang dapat dilakukan untuk mencegah potensi risiko pada prioritas utama.

\section{Kesimpulan}

Hasil dari evaluasi keselamatan dan kesehatan kerja pada Praktikum Perancangan Teknik Industri II dengan cara menganalisis potensi bahaya dan risiko menunjukkan bahwa masih terdapat potensi bahaya yang termasuk dalam tingkat risiko prioritas utama. Risiko bahaya yang paling tinggi adalah karena kebisingan yang terjadi pada saat praktikum yaitu sebesar $66 \%$ dari seluruh potensi bahaya yang berada pada tingkat risiko prioritas utama.

Untuk melakukan pengendalian risiko kecelakaan kerja dapat dilakukan dengan rekayasa teknik maupun rekayasa manjemen. Untuk kedepan dapat dilakukan rekayasa teknik dengan melakukan perubahan tata letak fasilitas dengan memberikan sekat. Pengendaliana risiko dengan rekayasa manjemen juga dapat dilakukan dengan mengubah jadwal dan membuat Standar Operasional Prosedur.

\section{Daftar Pustaka}

Amponsah,K., \& Taiwah.(2013).Occupational health and safety and sustainable development in 
Ghana.International Journal Bussines. Administration, Vol.4 (2), 74 - 78.

Chao,E.L., \& Henshaw.J.L.(2002).Job Hazard Analysis. OSHA 3071 revised. Occupational Safety and Health Administration.Washington: US Department of Labour.

Gopinath,V., \& Johansen,K.(2016).Risk Assessment Process for Collaborative Assembly - A Job Safety Analysis Approach.Procedia CIRP,Vol.44,199-203.

Fithri,P., \&Annisa,I.Q.2015.Analisis Intensitas Kebisingan Lingkungan Kerja pada Area Utilities Unit PLTD dan Boiler di PT Pertamina RU II Dumai.Jurnal Sains,Teknologi dan Industri, Vol 12,278-285.

Holt,A.S.J.(2001).Principles of Construction Safety.London: Blackwell science. London.

Jilca,K., \& Kitaw,D.(2017).Industrial Occupational Safety and Health Innovation for Sustainable Development.Engineering Science and Technology, an International Journal, Vol 20,372-380.

Olewsky,T., \& Snakard,M.(2017).Challenges in Applying Process Safety Management at University Laboratories.Journal of Loss Prevention in The Process Industries, Vol.49,209-214.

Rozenfeld,O.,Sacks,R.,Rozenfeld,Y.,\&Baum,H.(2010). Construction Job Safety Analysis.Safety Science,48,491-498.

Sholichah,M., \& Suliantoro,H.(2016).Analisis Risiko Kerja pada Pembuatan Nata De Coco dengan Metode Job Safety Analysis (JSA) di CV Sempurna Boga Makmur.Industrial Engineering Online Journal, Vol 5,4

Suryaningsih,Y.(2017).Pembelajaran Berbasis Praktikum sebagai Sarana Siswa untuk Berlatih Menerapkan Keterampilan Proses Sains dalam Materi Biologi.Jurnal Bio Educatio, Vol 2 (2),49 57.

Tarwaka.(2014).Manajemen dan Implementasi K3 di Tempat Kerja.Edisi ke-2. Surakarta,Harapan Press. www.bpjsketenagakerjaan.go.id.(2016).Diunduh 3Maret 2017. 